\title{
The histological changes induced by cytarabine on rabbits kidneys (with and without vitamin $\mathbf{E}$ administration)
}

\author{
S. Al-Jammas ${ }^{1}$ and A. Al-Saraj ${ }^{2}$ \\ College of Dentistry, University of Mosul, Mosul, Iraq \\ 1saifaljammas@uomosul.edu.iq, ${ }^{2}$ ayadrehman@gmail.com
}

(Received October 17, 2018; Accepted January 13, 2019)

\begin{abstract}
The present study was designed to determine the histological changes induced by Cytarabine drug on the structure of rabbits kidneys and the protective effects of vitamin $\mathrm{E}$ on these histological changes. The treated group with daily intraperitoneal dose of $(50 \mathrm{mg} / \mathrm{kg}$ body weight) of Cytarabine alone, showed a massive histological changes represented by renal tubular necrosis, glomerular atrophy and enlarged urinary spaces (widening of Bowman's spaces), infiltration of lymphocytes and macrophages within interstitium of the cortex, formation of hyaline cast in some of the tubular lumens as well as fibrosis and hemorrhage in the cortex were also observed. While the group that received a protective (800 IU of vitamin E) prior to each Cytarabine injection showed a significant improvement that represented by focal regions in the cortex with a normal renal tubules except for a cloudy cell swelling which is a reversible injury, also neither cortical hemorrhage nor hyaline cast formation were seen, in addition to presence of focal areas of normal glomeruli. The present study suggests that vitamin $\mathrm{E}$ is an effective chemo-protective agent against nephrotoxicity when used prior to each Cytarabine administration.
\end{abstract}

Keywords: Cytarabine, Rabbit's kidney, Vitamin E Available online at http://www.vetmedmosul.com

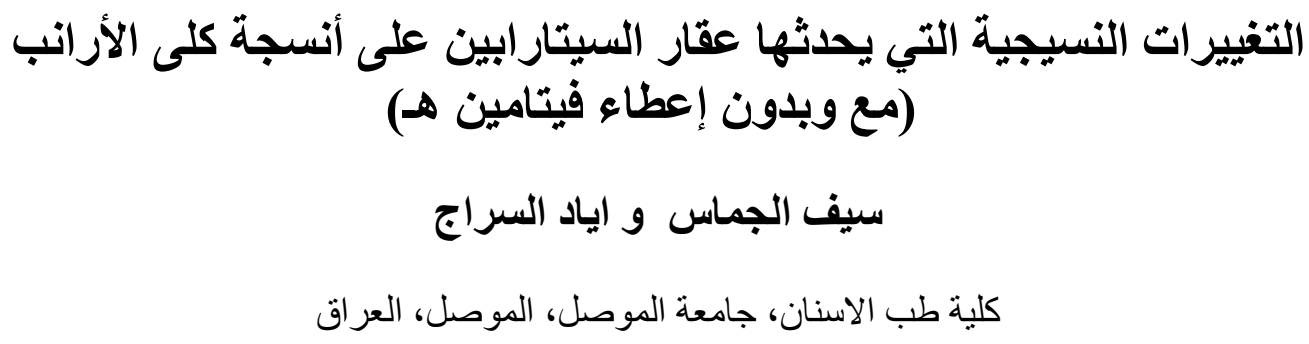

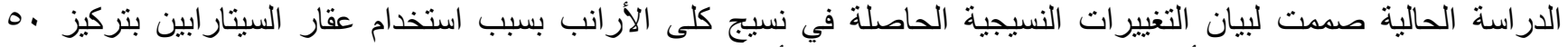

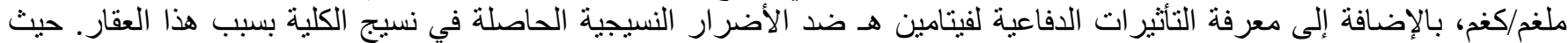

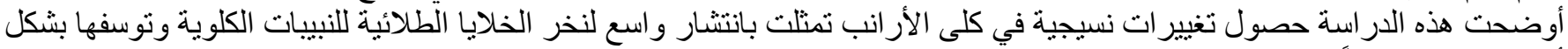

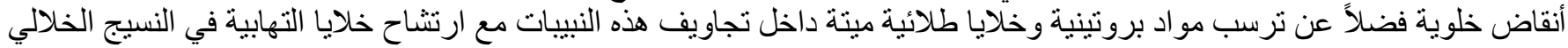

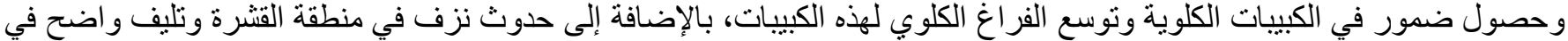

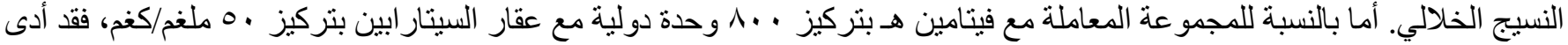

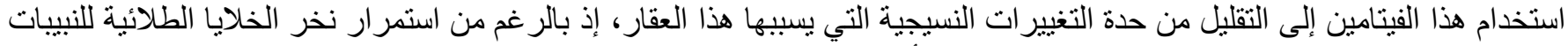

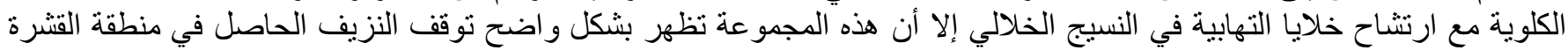

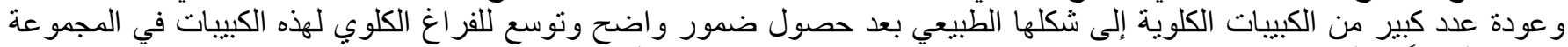

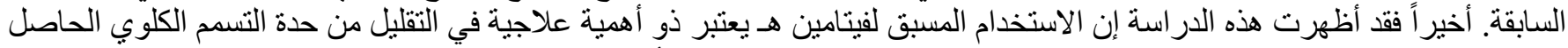
بسبب عقار السيتار ابين، وان هذه السمية تكون قابلة للتقليل باستخدام مضادات الأكسدة مثل فيتامين هـ. 


\section{Introduction}

Chemotherapy is a routine and successful treatment for many types of malignances (1). Cancer treatment was subjected to an important progress in last few years, when the oncology approaches had improved significantly for numerous patients. These patients whom suffered previously from chemotherapeutic drugs failures are now getting an important result with the reduced progression of cancer as well as increasing the rate of survival (2). Regardless of this significant progression in chemotherapy drugs for many malignant diseases, the nephrotoxicity stays the chief side effect and sometimes become a life threatening problem $(3,4)$. Cytarabine, known as Ara-C, is a chemotherapy drug (antimetabolite) used mainly in treatment of cancers of white blood cells like Non-Hodgkin lymphoma and acute Myeloid Leukemia. It causes cancer cells death by inhibition of DNA polymerase via competition with deoxycytidine triphosphate. Cytarabine is called cytosine arabinose because it joins an arabinose sugar with cytosine base (5). Cytosine is normally combining with a (deoxyribose sugar) to form deoxycytidine, which is a DNA component. Cytosine arabinoside is nearly similar to the cytosine deoxyribose (deoxycytidine) of the human to be incorporated inside human DNA but sufficiently different to terminate malignant cells, finally cancer cells would be killed by this mechanism (6). Acute renal injury (nephrotoxicity) is the most popular forms of renal diseases that may occur as consequences of cytotoxic treatment (7). The purpose of this study is to illustrate the histological changes induced by Cytarabine on the structure of rabbit's kidneys and the protective effects of vitamin $\mathrm{E}$ on these histological changes.

\section{Materials and methods}

\section{Laboratory animals}

The study is carried out on rabbits weighing $1.5-2.0 \mathrm{~kg}$, obtained from Pharmaceutical Control Department (Ministry of Health and Environment), aged three months, The rabbits were permitted to adapt to laboratory circumstance 5 days before starting the experiment, and caged in a temperature controlled chamber $\left(24 \pm 4^{\circ} \mathrm{C}\right)$ with a $12 \mathrm{hrs}$., light/dark cycle. They were permitted to drink tap water freely and daily fed by food pellet consisting of $20 \%$ protein and under good laboratory circumstances.

\section{Experimental design}

The rabbits were separated into three experimental groups $(n=6)$ and each one was given the following treatment; Group A: given $1 \mathrm{ml}$ of intraperitoneal injection of normal saline alone once a day for 1 week and served as a control group. Group B: given a daily intraperitoneal dose of $(50 \mathrm{mg} / \mathrm{kg}$ body weight) Cytarabine only for 1 week. Group C: given a daily oral dose of (800 IU of vitamin E) 5 hours before it receives the daily intraperitoneal dose of (50 $\mathrm{mg} / \mathrm{kg}$ body weight) Cytarabine for 1 week. The Intraperitoneal injections were given in the lower lateral part of the abdomen. The rabbits of all three groups were scarified after seven days under light ether anesthesia.

\section{Tissue preparation for histological study}

Kidneys of each rabbit were prepared for histological study by placing them in solution of $10 \%$ formalin for a period of 24 hours for fixation, after that the tissues were dehydrated using a gradual concatenations of alcohol solution $(30 \%-100 \%)$ for $(5 \mathrm{~min}$.) each. Then the tissue samples were cleared in 2 separated xylene changes prior to placing them in paraffin wax for final sectioning. Later the samples were cross sectioned at $5 \mu \mathrm{m}$ thickness, then it stained by hematoxylin and eosin (HE) stain to study the histological changes and compared to the control group using light microscope.

\section{Results}

Histological structure of the kidney sections in group A (control group) appeared to be absolutely normal as we could see normal structure of renal constitution (Figure 1). The kidney sections of group B (cytarabine treated group) showed renal tubular necrosis represented by sloughing and desquamation of the epithelial cells lining the renal tubules in the form of cellular debris (Figure 2). The glomeruli showed atrophy of the glomerular tuft and enlarged urinary spaces (Figure 3), interstitial nephritis is also represented by infiltration of inflammatory cells within interstitial tissue (Figure 4), infiltration of lymphocytes and macrophages within interstitium of the cortex (Figure 5), fibrosis in interstitial tissue is also seen (Figure 5) formation of hyaline cast in some of the tubular lumens (Figure 6) as well as hemorrhage in cortex was also observed (Figure 7). The kidney sections of group C (cytarabine treated group with vitamin $\mathrm{E}$ protection) showed no hemorrhage in cortex, no hyaline cast formation in tubular lumens and presence of focal areas of normal glomeruli (Figure 8), cloudy cell swelling of the tubular cells (Figure 8), it also showed a continuous destruction of renal tubules with sloughing and desquamation of the epithelial cells lining the renal tubules (Figure 9) infiltration of lymphocytes and macrophages within interstitium of the cortex is still observed (Figure 10). 


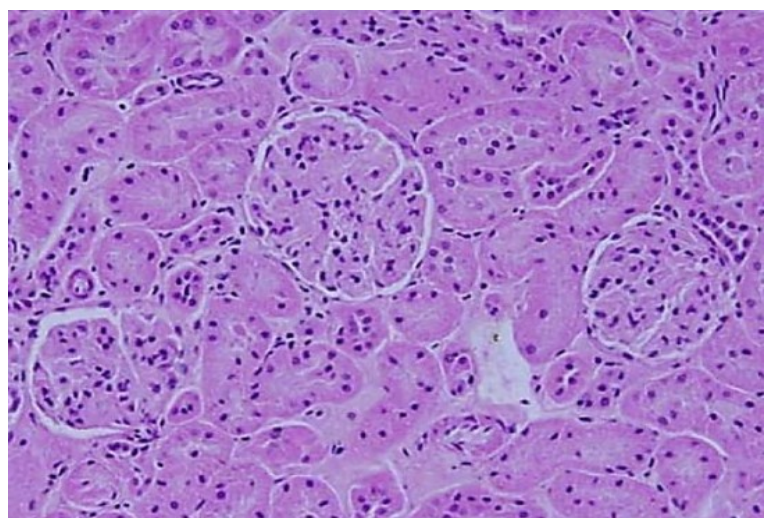

Figure 1: Histological section of rabbit's kidney tissue of the group A (control group) showed normal structure of renal constitution. HE, 400x.

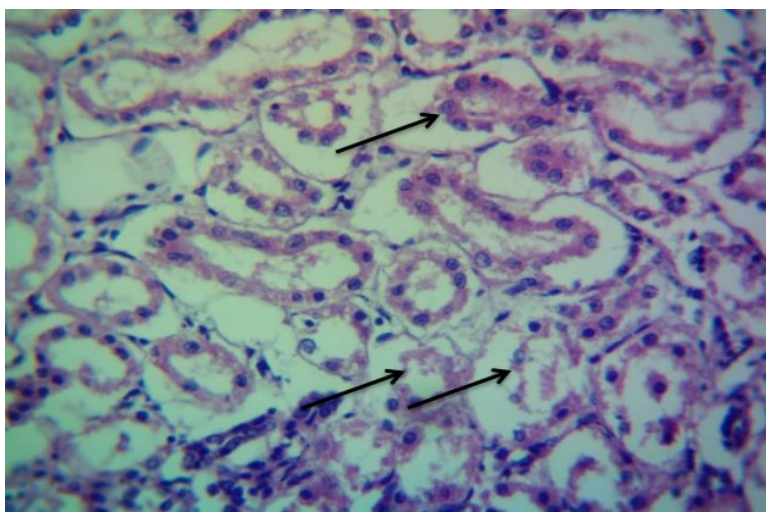

Figure 2: Histological section of rabbit's kidney tissue of the group B showed renal tubular necrosis represented by sloughing and desquamation of the epithelial cells lining the renal tubules as cellular debris (arrows). HE, 400x.

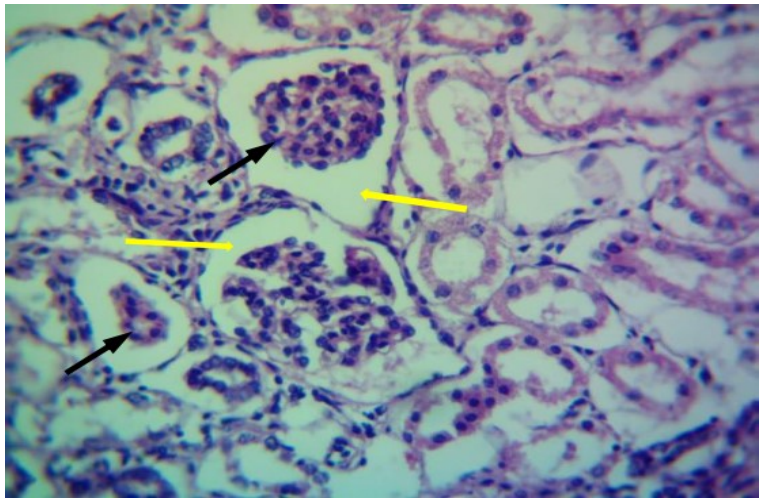

Figure 3: Histological section of rabbit's kidney tissue of the group B showed atrophy of the glomerular tuft (black arrows) and widening of the urinary space (yellow arrows). HE, 400x.

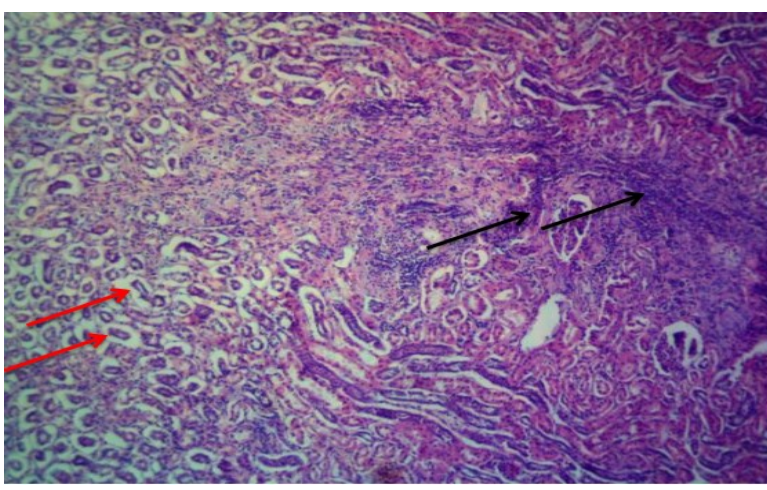

Figure 4: Histological section of rabbit's kidney tissue of the group B showed interstitial nephritis represented by infiltration of inflammatory cells within interstitium (black arrows) and necrosis of renal tubules (red arrows). HE, $100 \mathrm{x}$.

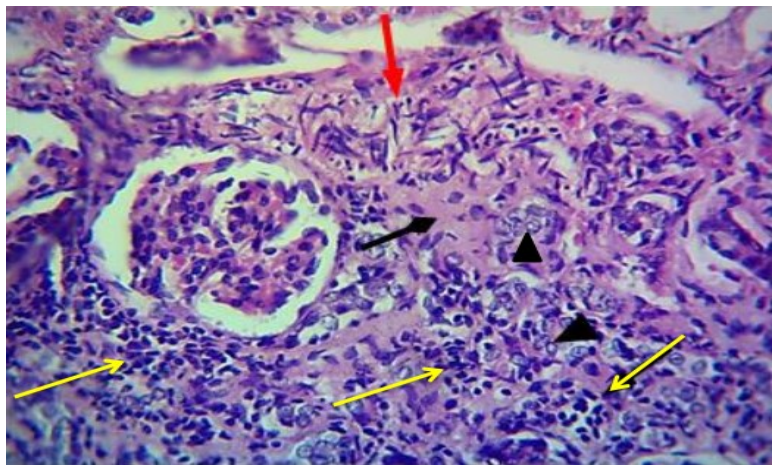

Figure 5: Histological section of rabbit's kidney tissue of the group B showed infiltration of lymphocytes within interstitium of the cortex (yellow arrows), macrophages less dominant (arrow heads), fibrosis in interstitial tissue (black arrow) due to hyperplasia of fibrocytes (red arrow). HE, 400x.

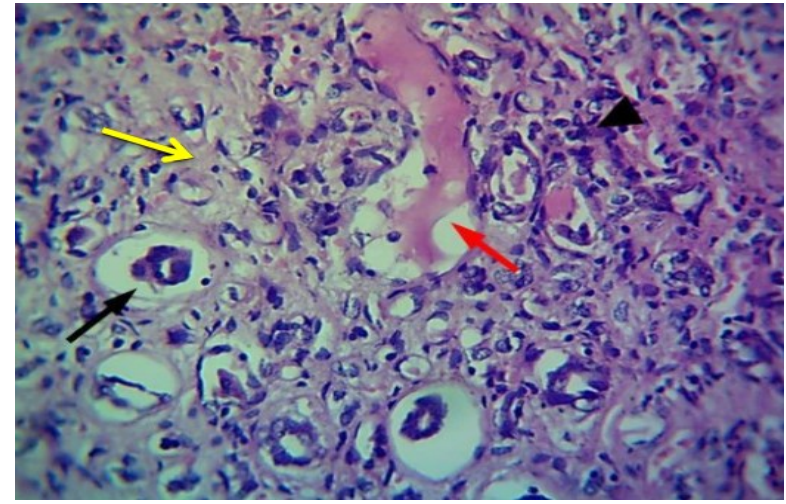

Figure 6: Histological section of rabbit's kidney tissue of the group B showed necrosis of renal tubules (black arrow), 
infiltration of mononuclear inflammatory cells (arrow head), fibrosis of interstitial tissue (yellow arrow) and formation of hyaline cast in some of the tubular lumens (red arrow). HE, 400x.

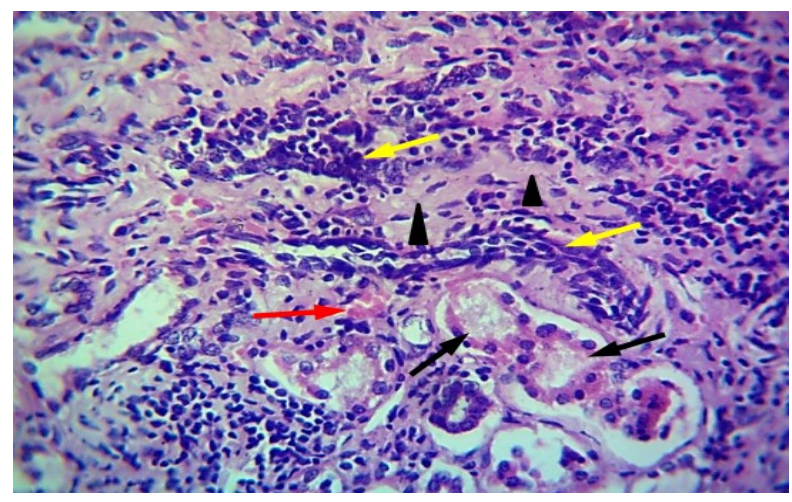

Figure 7: Histological section of rabbit's kidney tissue from group B, showed necrosis of renal tubules (black arrows), infiltration of lymphocytes (yellow arrows), fibrosis (arrow heads), in addition to focal area of hemorrhage (red arrow). HE, 400x.

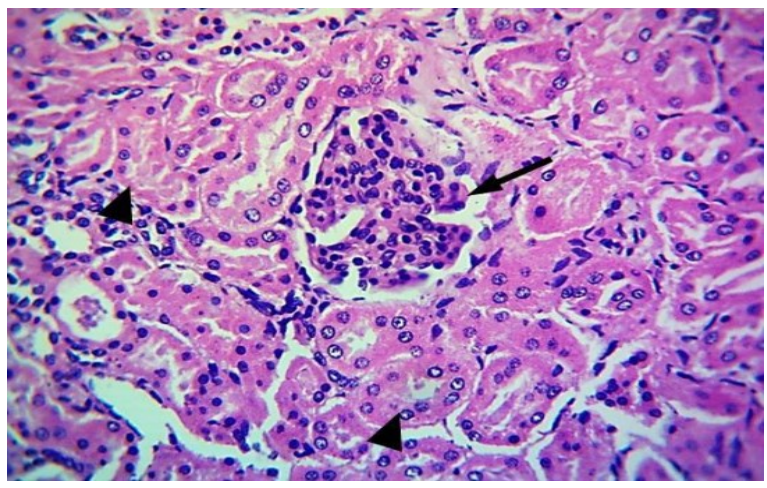

Figure 8: Histological section of rabbit's kidney from group $\mathrm{C}$, showed normal structure of glomerular tuft (arrow), with tubular cloudy cell swelling (arrow heads). HE, 400x.

\section{Discussion}

Most of the cytotoxic drugs that used for treatment of malignant tumors can cause a different histological change in the kidneys due to the role of the kidneys in metabolism and excretion of those toxic substances. These drugs can affect renal tubular cells, glomerulus or interstitium, with clinical manifestations that may range from elevation of serum creatinine to acute kidney injury (8).

This work regarded as the first experimental study focuses on the renal histological changes induced by Cytarabine and the protective effects of vitamin $\mathrm{E}$ against Cytarabine induced nephrotoxicity as most of the previous researches carried out on human patients, found a strong relation between high doses of cytarabine and renal insufficiency or renal failure (8), but these studies were focusing on clinical manifestations and parameters not histological changes, as well as no antioxidants like vitamin $\mathrm{E}$, were used in these experiments as a protective agent.

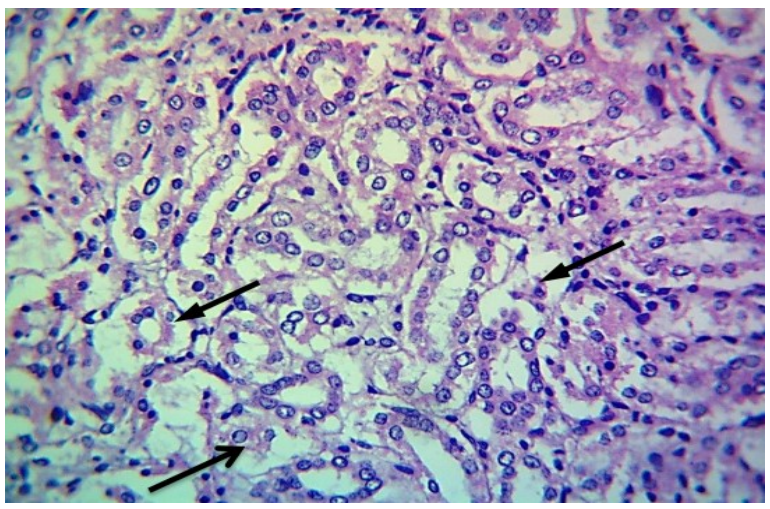

Figure 9: Histological section of rabbit's kidney from group $\mathrm{C}$, showed a continuous destruction of renal tubules with sloughing and desquamation of the epithelial cells lining the renal tubules as cellular debris (arrows). HE, 400x.

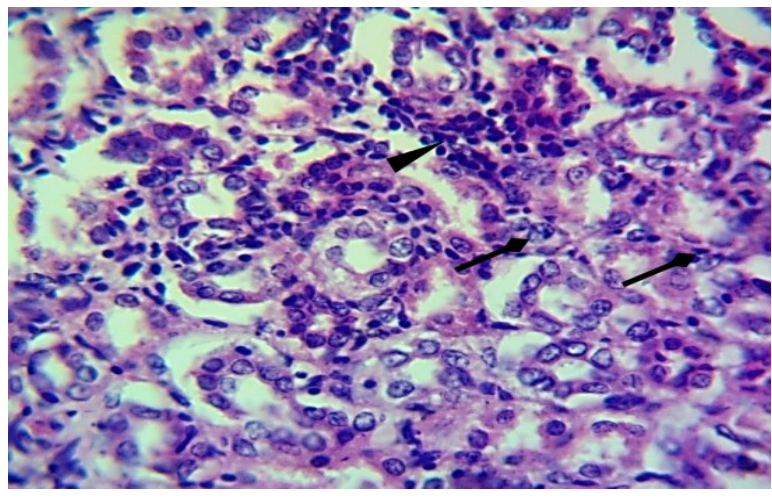

Figure 10: Histological section of rabbit's kidney from group $\mathrm{C}$, showed a continuous infiltration of lymphocytes (arrow head) and macrophages (black arrows). HE, 400x.

The nephrotoxicity observed in (group B) is represented by many histological changes, like renal tubular necrosis that represented by sloughing and desquamation of the epithelial cells lining the renal tubules, the glomeruli showed atrophy of the glomerular tuft and enlarged urinary spaces, interstitial nephritis represented by infiltration of inflammatory cells within interstitial tissue, formation of hyaline cast in some of the tubular lumens in addition to the fibrosis and hemorrhage which were also well observed.

Renal excretion of many anticancer agents needs transport by peritubular capillaries to permit entrance to 
basolateral surface of the epithelial cells of renal tubules. Then when these drugs reach basolateral membrane, they are transported via organic cation and anion transporters into the cells, then excreted by efflux transporters on the apical membrane into tubular lumens. Any inhibition or dysfunction of the kidney efflux transporters can lead to accumulation of the drug inside the cells of renal tubules which in turn leads to drug-induced nephrotoxicity represented by renal tubular necrosis and sloughing of the epithelial cells lining the renal tubules $(9,10)$.

The kidney is a metabolic organ that oxidizes drugs into different metabolites through a specific enzymatic system situated inside the renal parenchyma . Kidney tissues could be damaged by a number of these metabolites via different mechanisms like reactive oxygen species formation and generation of oxidative stress (11). These reactive oxygen species (ROS) generated by Cytarabine cause a chronic inflammatory reaction within the renal tissue that leads to infiltration of mononuclear cells into the interstitium and production of profibrotic mediators that are released from the mononuclear cells such as macrophages, these macrophages play an important role in renal interstitial fibrosis through production of fibro-genic factors that mediate the induction of myofibroblast cells to produce extracellular matrices $(12,13)$.

Oxidative Stress on the other hand may alter renal hemodynamics, as it impairs renal blood flow or increase vascular resistance which results in elevation of the blood pressure that is difficult to control leading to rapture of renal capillaries and hemorrhage $(14,15)$.

The glomerular atrophy and enlarged urinary spaces are formed because the concentration of drug in blood is influenced with capillary constriction resulting in reduction of the glomerular filtration of the drug that diminishes its adverse effects and protects the tubular cells. This in turn can finally leads to glomerular tuft atrophy and the widening of the urinary spaces (16).

Hyaline cast may be formed due to the reduced tubular reabsorption of protein, causing the accumulation of these proteins within the tubular lumens. This casts then cause an increased intratubular pressure and a reduction in the glomerular filtration rate (17).

Regarding (group C) which is treated with an antioxidant (vitamin E) prior to each Cytarabine injection, the histological changes observed in this group showed less severity than that of Group B, as despite of the continuous destruction of renal tubules in many cortical regions, but we can still note another regions in the cortex with a nearly normal renal tubules except for a cloudy cell swelling which is a reversible injury of the tubular cells characterized by cellular swelling that occur due to injury of their cellular membranes affecting ionic transfer causing the cytoplasm to become cloudy and fluid to accumulate between cells resulting in swelling of these tissues (18). Also, these sections showed no hemorrhage within cortex, no hyaline cast formation in tubular lumens, in addition to presence of focal areas of normal glomeruli.

Many clinical researches stated that administration of antioxidants like vitamin $\mathrm{E}$ with chemotherapeutic drugs reduces the adverse effects of these drugs and protect normal tissue without decreasing tumor control ability (19). The present study results were in agreement with those studies, as it concluded that vitamin $\mathrm{E}$ administration would be effective in protecting against cytarabine-induced tissue damage in rabbit's kidney and this protection could be attributed to the reason of; the toxic effects of cytarabine is reduced by a compensatory mechanism involving vitamin $\mathrm{E}$ by the induction of (antioxidant-enzyme) activity that follows the cytarabine injection (20). Also, administration of vitamin $\mathrm{E}$, as an antioxidant can inhibit the chain reactions of free radicals created by cytarabine or may scavenged the free radicals prior it reached their targets to alter the glomerular renal functions, thus preventing cellular damage to the renal tissue caused by Cytarabine $(21,22)$.

From the mentioned results, this study concluded that vitamin $\mathrm{E}$ is an effective chemo-protective agent against nephrotoxicity and renal tubular dysfunction induced by cytarabine without affecting the antineoplastic activity of Cytarabine. However, Further studies are required to see the degree of protection provided by Vitamin E at different doses and at different times prior to each Cytarabine administration.

\section{References}

1. Desai AG, Qazi GN, Ganju RK, El-Tamer M, Singh J, Saxena AK, Bedi YS, Taneja SC, Bhat HK. Medicinal Plants and Cancer Chemoprevention. Curr Drug Metab. 2008;9(7):581-591. DOI: 4160808

2. Sahni V, Choudhury D, Ahmed Z. Chemotherapy-associated renal dysfunction. Nat Rev Nephrol. 2009;5(8):450-462. DOI: $10.1038 /$ nrneph.2009.97

3. Perazella MA, Moeckel GW. Nephrotoxicity from chemotherapeutic agents: Clinical manifestations, pathobiology, and prevention/therapy. Semin Nephrol. 2010;30(6):570-581. DOI: 10.1016/j.semnephrol.2010.09.005

4. Finkel KW, Foringer JR. Renal disease in patients with cancer. Nat Clin Pract Nephrol. 2007;3(12):669-678. DOI: $10.1038 /$ ncpneph0622.

5. Wang WS, Tzeng CH, Chiou TJ, Liu JH, Hsieh RK, Yen CC, Chen PM. High-dose Cytarabine and Mitoxantrone as Salvage Therapy for Refractory Non-Hodgkin's Lymphoma. Jpn J Clin Oncol. 1997;27(3):154-157.

DOI: $10.1093 / \mathrm{jjco} / 27.3 .154$

6. Konda N, Prashanth P, Arvind G, Shah S. Pharmaceutical development and compatibility studies on cytarabine injection. Asian J Pharm Clin Res. 2013;3(6):42-145. DOI: 0974-2441

7. Norbert L. Nephrotoxicity of recent anti-cancer agents. Clin Kidney J. 2014;7(1):11-22. DOI: $10.1093 / \mathrm{ckj} / \mathrm{sft} 135$ 
8. Perazella MA. Onco-Nephrology: Renal Toxicities of Chemotherapeutic Agents. Clin J Am Soc Nephrol. 2012;7(10):17131721.

DOI: $10.2215 /$ CJN.02780312

9. Morrissey KM, Stocker SL, Wittwer MB, Xu L, Giacomini KM. Renal transporters in drug development. Annu Rev Pharmacol Toxicol. 2013;53:503-529.

DOI: 10.1146/annurev-pharmtox-011112-140317

10. Giacomini KM, Huang SM, Tweedie DJ, Benet LZ, Brouwer KL, Chu $\mathrm{X}$, Dahlin A, Evers R, Fischer V, Hillgren KM, Hoffmaster KA, Ishikawa T, Keppler D, Kim RB, Lee CA, Niemi M, Polli JW, Sugiyama Y, Swaan PW, Ware JA, Wright SH, Yee SW, ZamekGliszczynski MJ, Zhang L. Membrane transporters in drug development. Nat Rev Drug Discov. 2010; 9(3):215-236. DOI: $10.1038 / \mathrm{nrd} 3028$

11. Perazella MA. Renal vulnerability to drug toxicity. Clin J Am Soc Nephrol. 2009;4(7):1275-1283. DOI: $10.2215 /$ CJN.02050309

12. Cruz CM, Rinna A, Forman HJ, Ventura AL, Persechini PM, Ojcius DM. ATP activates a reactive oxygen species-dependent oxidative stress response and secretion of proinflammatory cytokines in macrophages. J Biol Chem. 2007;282:2871-2879.

DOI: $10.1074 / j b c . M 608083200$

13. Rodríguez-Iturbe B, Vaziri ND, Herrera-Acosta J, Johnson RJ. Oxidative stress, renal infiltration of immune cells, and salt-sensitive hypertension: all for one and one for all. Am J Physiol Renal Physiol. 2004;286(4):606-616. DOI: 10.1152/ajprenal.00269.2003

14. Erdinç M, Erdinç L, Nergiz Y, Kelle İ. The Effects of Nifedipine on Renal Perfusion Pressure and Kidney During Cisplatin-Induced Nephrotoxicity in Rats. Cilt. 2007;34(4):248-253. DOI: 10.1161/01.hyp.11.5.452
15. Al-Jammas SA, Al-Hubaity AY. The Effects of Vitamin C on the Structure of Wistar Albino Rat's kidney. Med J Tikrit. 2011;2(172),116-119.

16. Steven A, Lowe J. Histology Gower Medical publishing. Libyan J Med. 1997;2:1-16.

17. Racusen LC, Fivush BA, Li YL, Slatnick I, Solez K. Dissociation of tubular cell detachment and tubular cell death in clinical and experimental "acute tubular necrosis". Lab Invest. 1991;64(4):546456.

DOI: 1673163

18. Abdelhalim MAK, Jarrar BM. The appearance of renal cells cytoplasmic degeneration and nuclear destruction might be an indication of GNPs toxicity. Lip Heal Dis. 2011;10:147. DOI: 10.1186/1476-511X-10-147.

19. Lawenda BD, Kelly KM, Ladas EJ, Sagar SM, Vickers A, Blumber JB. Should supplemental antioxidant administration be avoided during chemotherapy and radiation therapy?. J Natl Cancer Inst. 2008; 100:773-783

DOI: $10.1093 /$ jnci/djn148.

20. Dillioglugil MO , Maral KH, Gulkac MD, Ozon KA, Ozdogan HK, Acar O, Dillioglugil O. Protective effects of increasing vitamin E and a doses on cisplatin-induced oxidative damage to kidney tissue in rats. Urol Int. 2005;75(4):340-344. DOI: $10.1159 / 000089171$

21. Tarladacalisir YT, Kanter M, Uygun M. Protective effects of vitamin $\mathrm{C}$ on cisplatin-induced renal damage: a light and electron microscopic study. Ren Fail. 2008;30(1):1-8. DOI: $10.1080 / 08860220701742070$

22. Hajian S, Rafieian-Kopaei M, Nasri H. Renoprotective effects of antioxidants against cisplatin nephrotoxicity. J Nephropharmacol. 2014;3(2):39-42.

DOI: 28197460 